\title{
Probing relation between solar activities and seismicity
}

\author{
Bijan Nikouravan $^{1,2,3 *}$, J. J. Rawal ${ }^{3}$, Rahman Sharifi ${ }^{4}$ and Mahmoud Nikkhah ${ }^{5}$ \\ ${ }^{1}$ Department of Physics, Astrophysics, Varamin Pishva Branch, Islamic Azad University (IAU), Varamin, Iran. \\ ${ }^{2}$ Department of Physics, Astrophysics, University of Malaya (UM), 50603 Kuala Lumpur, Malaysia. \\ ${ }^{3}$ The Indian Planetary Society (IPS), Mumbai, 400092, India, 400092 Mumbai, India. \\ ${ }^{4}$ Department of Geology, Science and Research Branch, Islamic Azad University, Tehran, Iran. \\ ${ }^{5}$ Department of Civil Engineering, Semnan Branch, Islamic Azad University, Semnan, Iran.
}

\begin{abstract}
Accepted 07 May, 2012
In this paper, we studied the relationship between sunspots numbers (SNs), solar $10.7 \mathrm{~cm}$ radio flux (SRF), solar irradiance (SI), solar proton events (SPEs) and local earthquakes. The location of the study is selected in Iran area and all earthquakes data chosen for $M \geq 4$ from 1970 to 2010 . The study reveals the following conclusions: (i) The total number of local earthquakes in maximum years of solar activities is greater than the minimum years of solar activities from 1964 to 2010, (ii) The total local earthquakes frequency (EF) in the maximum period of solar activities is very close to the maximum annual means of sunspots numbers, (iii) The total local EF in the maximum period of solar activity is very close to the maximum annual means of SPE with negative correlation coefficient, (iv) The local earthquakes in the minimum period of solar activities is very close to the minimum annual means of sunspots numbers with negative correlation and (v) The local earthquake in the minimum period of solar activities is very near to SRF with negative correlation.
\end{abstract}

Key words: Solar activities, sunspots, solar proton events, solar irradiance, earthquake.

\section{INTRODUCTION}

The sun as the largest and most active object near to earth is located in the centre of the solar system. It contains $99.9 \%$ of the total mass of solar system. Not surprisingly, the sun dominates most events on earth, including our climate (Manuel et al., 2002). Different energies, wavelengths and charged particles escape from the Sun and get entered into all inner and outer planets of the solar system. The radiations emitted from sun not only have very serious effects on the earth atmosphere, but also affect the earth surface. As evidence are; low level clouds, ocean temperatures, land temperatures, tropospheric temperatures, and earthquakes (Courtillot et al., 2007). In the last four decades, many authors suggested the different effects of solar activities in Earth and earthquakes. Simpson (1968), Sitinskiy

*Corresponding author. $\quad$ E-mail: nikou@um.edu.my,
bijan_nikou@yahoo.com.

(1973, 1998), Khain and Khalilov (2007, 2009), Lursmanashvili (1972) and Ip (1976) carried out series of researches on the influence of solar activity on the earth seismicity. Odintsov (2006) and Zhang (1998) worked on the long period tendency in global earthquake geomagnetic activity and some simple relationships between solar activities and global number of earth-quakes ( $M \geq 4$ ). However few studies such as Gousheva et al. (2003) were considered for a country confined or local area earthquakes. Hence, our study is focused on exploring the relationships between solar activities such as sunspots numbers (SNs), solar $10.7 \mathrm{~cm}$ radio flux (SRF), solar irradiance (SI), solar proton events (SPEs) and local earthquakes for magnitude $M \geq 4$, in country confined local seismicity. The selected area is Iran which has one of the seismic and active regions. This study can be explored for different active regions (China, India and New Zealand considered by the first author with good results are not mentioned here). We assumed that: 1The Earth is not a homogeneous isotropic object but 


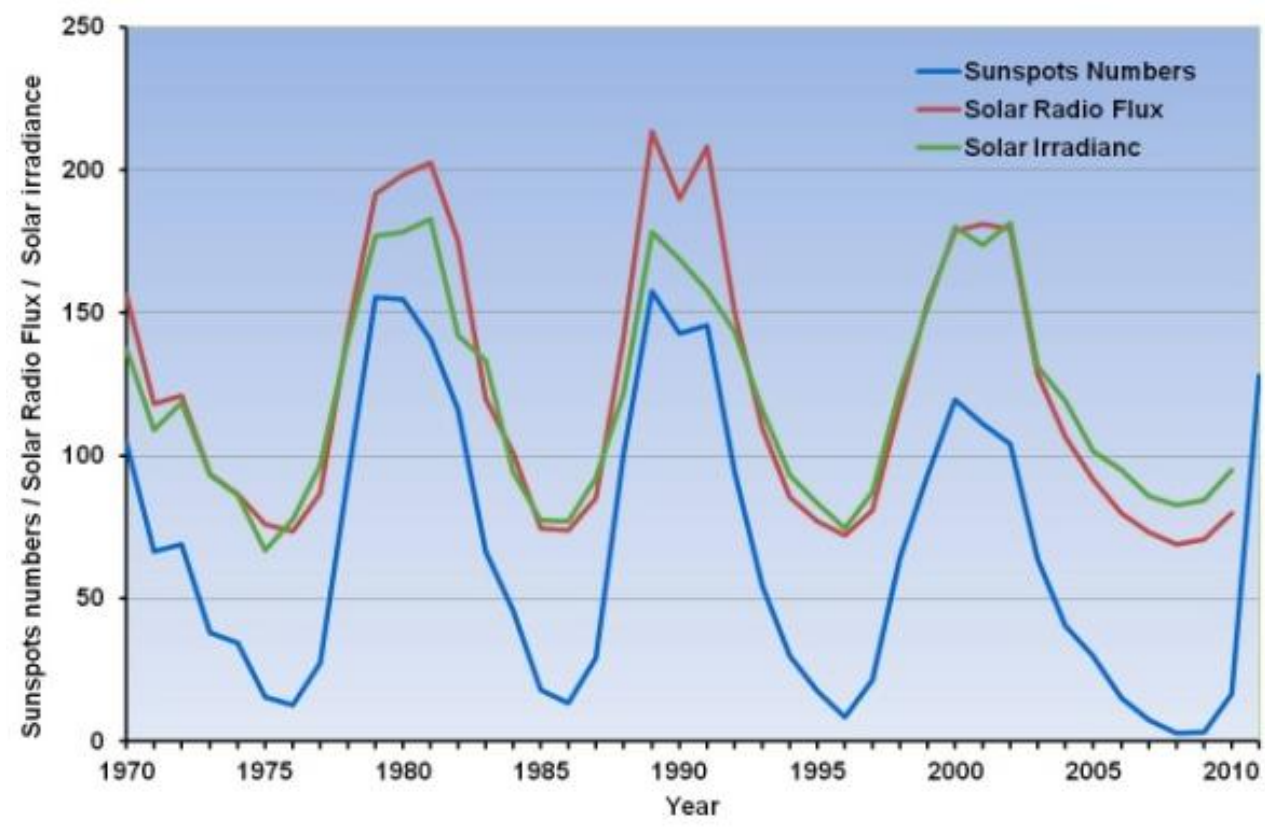

Figure 1. The variation of solar activities (1970-2010).

one with different structure of plate tectonics and properties, therefore, it is expected that different regions will show unlike responses. 2- The earthquakes are not only caused by internal effects (such as subsidence, volcanic and tectonic effects) but can also be triggered by some external effects such as solar activities and cosmic rays. To compare, the internal effects are stronger than the external effects. Within the framework of this study, a total of 40 years earthquake data (from 1970 up to the end of 2010 and some part of 2011) has been selected, and some relationship between solar activities and number of local earthquakes are developed. More research work on the relationship between solar activities and earthquake still need to be considered but in this research, we mentioned a simple physical reason in the discussion and conclusion section.

\section{DATA}

Here we pay attention only for SN, SRF, SI and also for high energy SPE $(\geq 10 \mathrm{MeV})$. All SNs data are available from Solar Influences Data Analysis Centre (SIDC) through 1970-2010. The surface regions near sunspots emit stronger radiation with wavelength $\lambda=10.7 \mathrm{~cm}$ as SRF. Also all SRFs data (1970-2010) are available from the National Oceanic and Atmospheric Administration (NOAA). The Earth also receives a total amount of radiation energy. The average incoming solar radiation is called the solar irradiance (SI) and all data also have been collected from historical total solar irradiance (TSI). Moreover, solar activities produce and emit very high energetic protons $(\geq 10 \mathrm{MeV})$. These charged particles arrive to Earth and enter the atmosphere over the Polar Regions and much enhanced ionization is produced at altitudes below $100 \mathrm{k}$. These high energetic protons can penetrate the Earth's magnetic field and cause ionization in the ionosphere. To select SPEs data, we used integral 5-minute averages for energies ( $\geq 10 \mathrm{MeV})$, given in Particle Flux Units (pfu). These data are available from issues of NOAA SESC (2000). Also the time period of 1976-2010 which are covering over 5 solar cycles 20, 21, 22, 23 and a part of 24, except 1996 and 2010 are provided by (http://www.swpc.noaa.gov/ Data/index.html).

The most and well known active regions in earthquake are Iran, Japan, Turkey, India, Australia, New Zealand, Italy, China, Indonesia and Philippines. All earthquake data also have been taken from IRIS for $M \geq$ and only for Iran zone.

\section{SOLAR ACTIVITIES, EARTHQUAKE FREQUENCY AND CORRELATIONS}

Solar activities (SNs, SRFs, SIs and SPEs), show a periodic variation approximately with 11 years and considered in exact maximum and minimum years of sunspots. The exact values here are defined as accurate values of SRF, SI and SPE in the maximum and minimum years of solar activities. The variations of $\mathrm{SN}$, SRF and SI from 1970 to 2010 are shown in Figure 1.

The 12 months running means of the earthquakes $(M \geq 4)$ from first of January 1970 to the end of December 2010 is measured. For more precise 
Table 1. The total number of earthquakes in maximum and minimum years of solar activities.

\begin{tabular}{|c|c|c|c|c|c|c|c|c|c|}
\hline \multirow{2}{*}{$\begin{array}{c}\text { Sunspots } \\
\text { cycles }\end{array}$} & \multirow{2}{*}{$\begin{array}{l}\text { Years of } \\
\text { start-finish }\end{array}$} & \multicolumn{2}{|c|}{ Years of sunspots } & \multirow{2}{*}{ SNs } & \multirow{2}{*}{ SRF } & \multirow[b]{2}{*}{ SI } & \multirow{2}{*}{ SPE } & \multirow[b]{2}{*}{ EF } & \multirow[b]{2}{*}{$(M \geq)$} \\
\hline & & Maximum & Minimum & & & & & & \\
\hline \multirow{2}{*}{18} & \multirow{2}{*}{$1944-1954$} & 1947 & - & 151.6 & - & 1361.1124 & - & & - \\
\hline & & - & 1954 & 4.4 & 702 & 1360.7617 & - & & - \\
\hline \multirow{2}{*}{19} & \multirow{2}{*}{ 1954-1964 } & 1957 & - & 190.2 & 2326 & 1361.4442 & - & & - \\
\hline & & - & 1964 & 10.5 & 726 & 1360.8296 & - & & 63 \\
\hline \multirow{2}{*}{20} & \multirow{2}{*}{$1964-1976$} & 1968 & - & 105.9 & 1491 & 1361.2476 & 60524 & & 71 \\
\hline & & - & 1976 & 12.6 & 734 & 1360.6678 & 12 & & 71 \\
\hline \multirow{2}{*}{21} & \multirow{2}{*}{$1976-1986$} & 1979 & - & 155.4 & 1917 & 1361.4080 & 1711 & & 161 \\
\hline & & - & 1986 & 13.4 & 740 & 1360.7749 & 297 & & 78 \\
\hline \multirow{2}{*}{22} & \multirow{2}{*}{ 1986-1996 } & 1989 & - & 157.6 & 2134 & 1361.2159 & 67974 & & 79 \\
\hline & & - & 1996 & 8.6 & 720 & 1360.8329 & 0 & & 118 \\
\hline \multirow{2}{*}{23} & \multirow{2}{*}{ 1996-2008 } & 2000 & - & 119.6 & 1787 & 1361.5148 & 40340 & & 98 \\
\hline & & - & 2008 & 2.9 & 690 & 1360.8568 & 0 & & 153 \\
\hline
\end{tabular}

Note: SNs, Sunspot numbers; SRF, solar radio flux; SI, solar irradiance; SPE, solar proton events; EF, earthquake frequency.

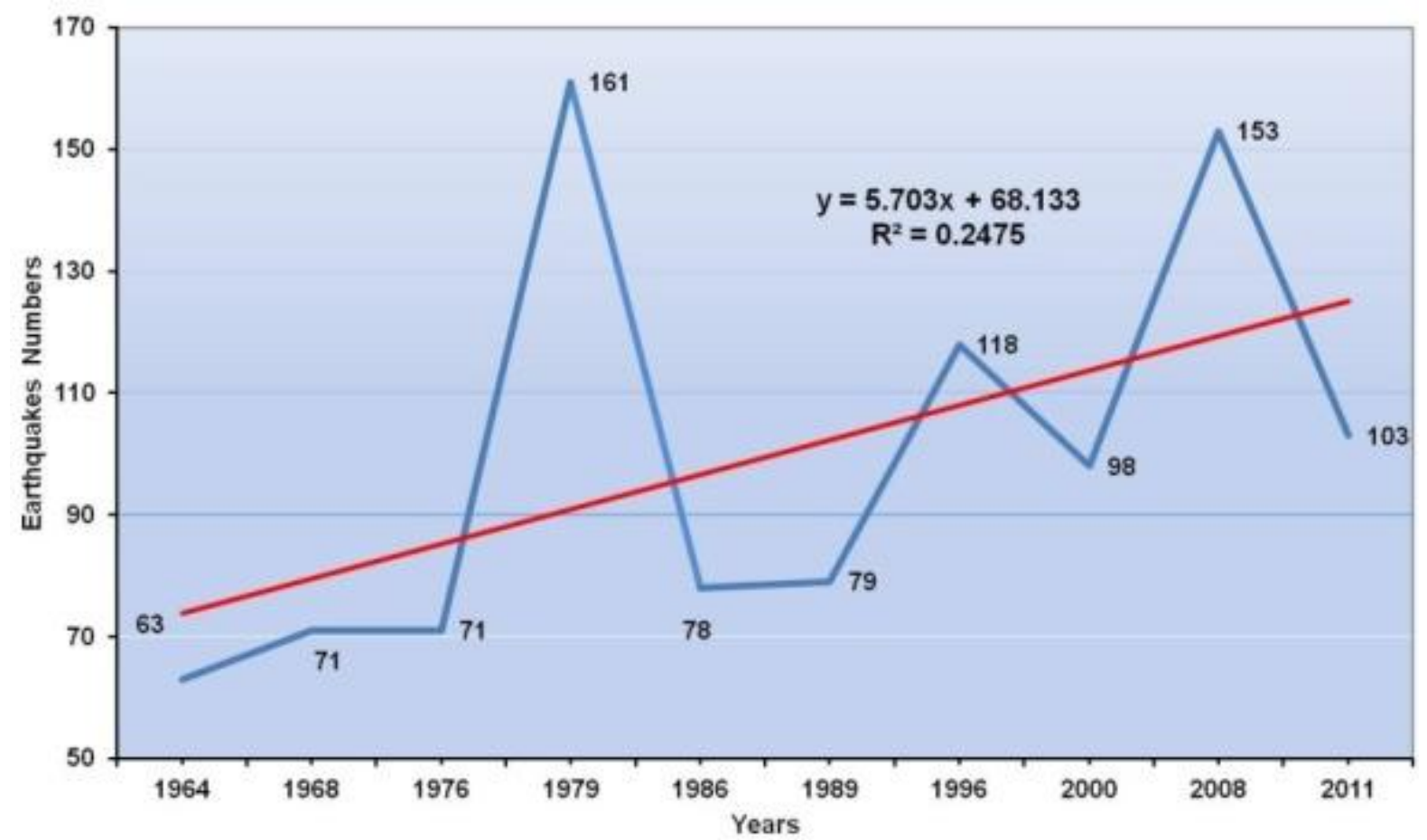

Figure 2. Earthquakes frequencies in maximum and minimum years of solar activities.

consequence, all standard magnitude's types with preferred catalog applied are from the NEIC PDEs (Table 1).

To illustrate the variation in number of earthquake events from first of January 1964 to the end of July 2011, we applied simple linear regression method. With respect to Figure 2, we note increasing number of earthquakes in each solar cycle with a simple linear positive regression 
Table 2. The correlation relation between solar activities and earthquakes ( $M \geq$ ).

\begin{tabular}{llcccl}
\hline Number & Correlation relations & Correlation & $\boldsymbol{R}^{2}$ & $\boldsymbol{R}$ & Linear relationship \\
\hline 1 & SPE-EF(Max) & -0.98 & 0.9526 & 0.976 & $\mathrm{y}=-0.0013 \mathrm{x}+159.42$ \\
2 & SNs-EF(Min) & -0.98 & 0.9651 & 0.982 & $\mathrm{y}=-7.8001 \mathrm{x}+178.13$ \\
3 & SRF-EF(Min) & -0.96 & 0.9277 & 0.9631 & $\mathrm{y}=-1.6461 \mathrm{x}+1291.8$ \\
4 & SI-EF(Min) & 0.86 & 0.7479 & 0.864 & $\mathrm{y}=391.42 \mathrm{x}+532526$ \\
5 & SPE-EF(Min) & -0.5 & 0.2527 & 0.502 & $\mathrm{y}=-0.1307 \mathrm{x}+115.1$ \\
\hline
\end{tabular}

Note: SNs, Sunspot numbers; SRF, solar radio flux; SI, solar irradiance; SPE, solar proton events; EF, earthquake frequency.

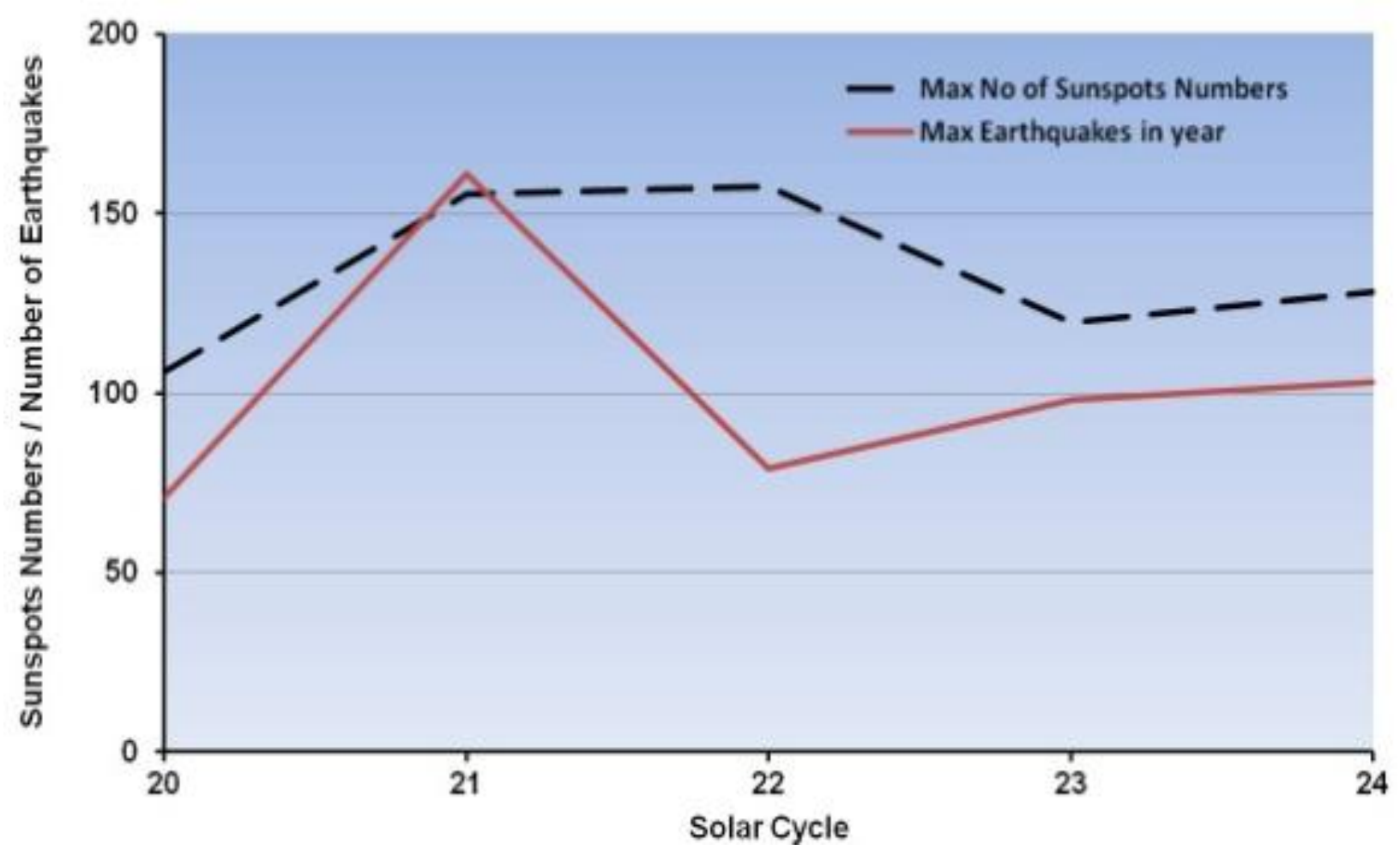

Figure 3. Variation of maximum annual means of SN (dotted line) and the EFs (solid line) in solar cycles (20-24).

slope. The linear relationship between maximum and minimum years of solar activities (SN, SRF, SI and SPE) and EF considered from 1970 to 2010 which are displayed in Table 2.

The maximum annual means of SNs and EF for solar cycles 20, 21, 22, 23, and part of 24 in the Iran region is also considered (Figure 3 ). The distribution number of earthquakes in these periods of solar cycles is very similar to the variation of sunspots numbers. The horizontal and vertical axis represents solar cycles and maximum annual means of SNs and EF respectively. The solid line represents the EF while the dotted line represents the maximum annual means of SNs. In the same period, the relation between maximum annual means of SPE (divided by 1000) and earthquake frequency is also considered.
In Figure 4 the dotted and solid lines show the maximum annual means of SPE and the EF in each cycle, respectively. The distribution of maximum number of earthquakes with number of SPEs (Figure 5) in each solar cycle, show a good values of $R=0.976$ and $R^{2}=$ 0:95.

Figure 6 simply show a very good connection between minimum years of SNs and EFs with strong and negative correlation coefficients of $R=-0: 98$ and. $R^{2}=0: 96$

The relationship between minimum years of SRF and EF also indicate high correlation coefficients of negative value $R=-0.96$. The correlations relation between $\mathrm{SI}$ and $E F$ in the minimum years of solar activities, illustrate a good value of $R=0.86$ for years of solar activities. The correlation between SPE and EF still shows negative and significant value but not very strong with coefficients of $R$ 


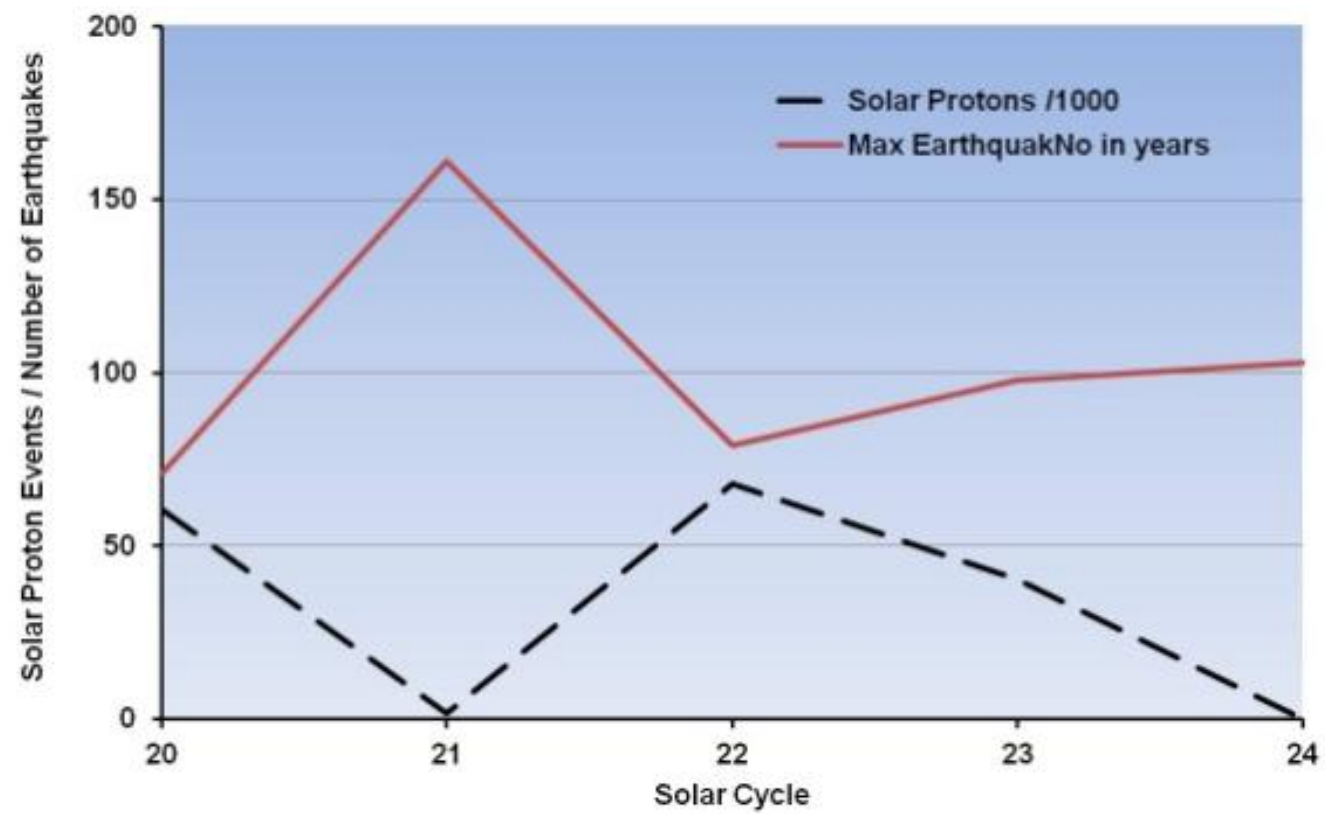

Figure 4. Variations of maximum annual means of SPEs (dotted line) and EFs (solid line) in solar cycles (20-24).

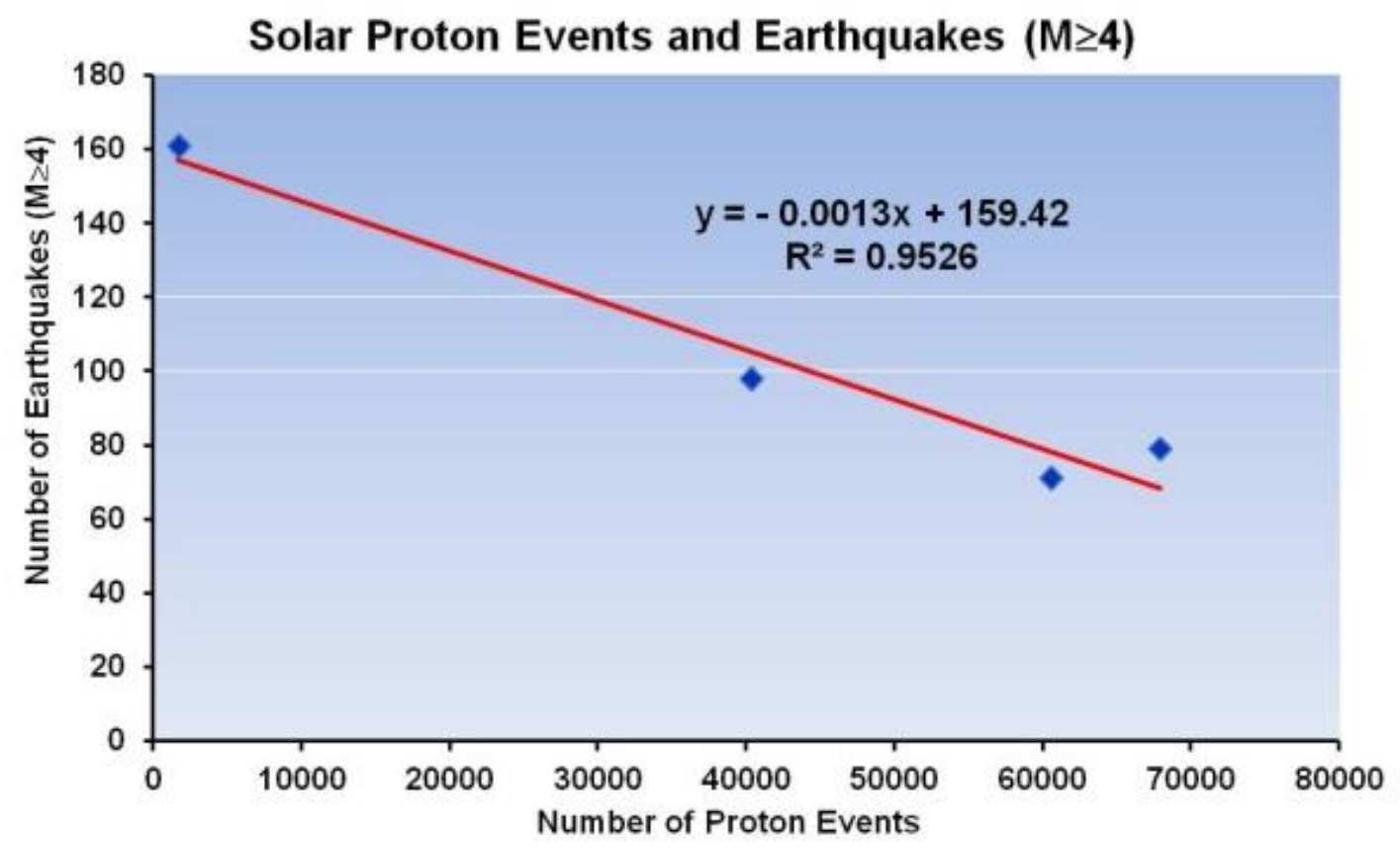

Figure 5. Number of SPEs and number of maximum earthquakes in each cycle.

$=-0.50$ (not shown here).

\section{DISCUSSION}

A quick look at the data in Tables 1 and 2, show good correlation coefficients. The above analysis and results can be concluded for earthquake frequencies $(M \geq 4)$ as follow:

1. The total number of local EF, in the maximum years of solar activities is greater than the minimum years of solar activities in the period of 1964-2010 (Table 3).

2. In the maximum years of solar activities, the total 


\section{Sunspot-Earthquakes $(M \geq 4)$}

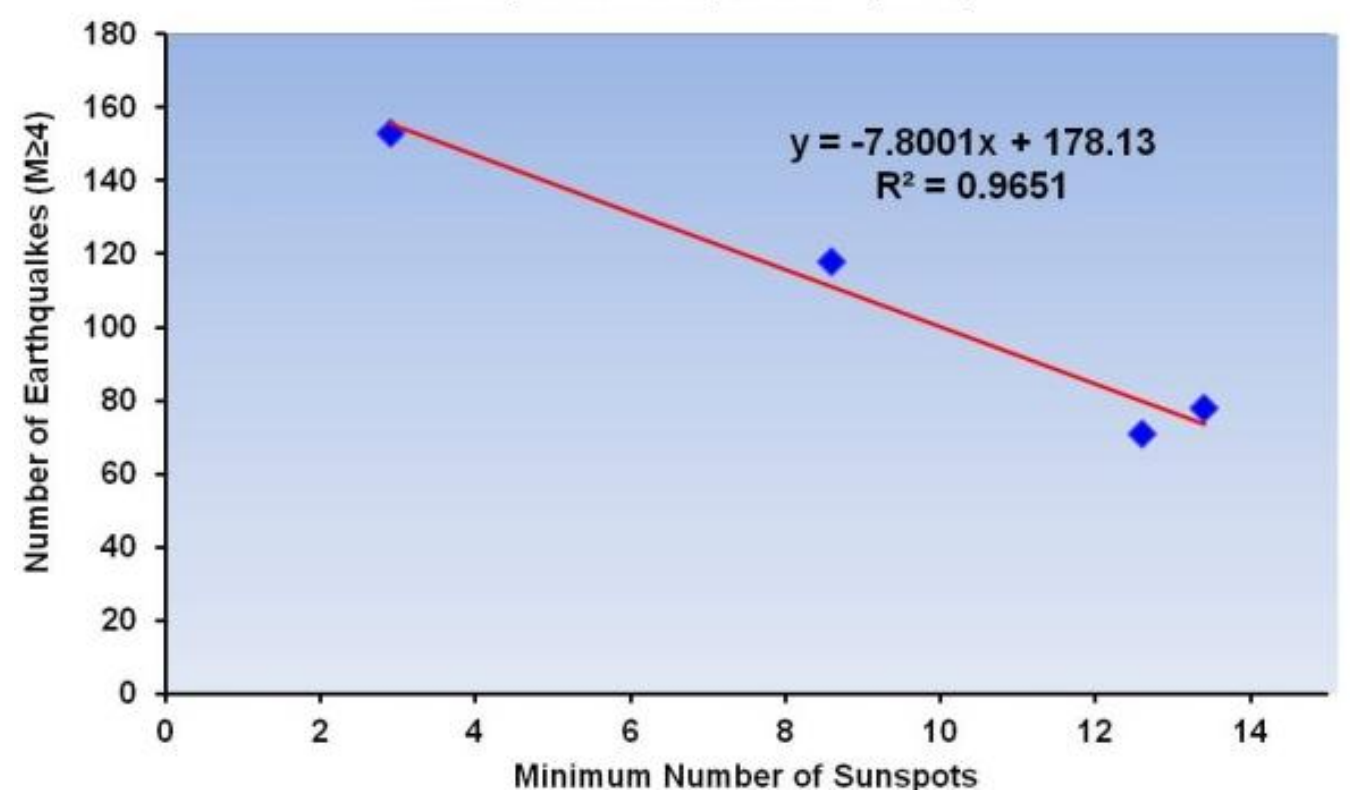

Figure 6. Number of SPEs and number of maximum earthquakes in each cycle.

Table 3. The total number of Earthquakes in minimum and maximum years of solar activities.

\begin{tabular}{cccc}
\hline Minimum year & EF (Minimum year) & Maximum year & EF (Maximum year) \\
\hline 1964 & 63 & 1968 & 71 \\
1976 & 71 & 1979 & 161 \\
1986 & 78 & 1989 & 79 \\
1996 & 118 & 2000 & 98 \\
2008 & 153 & 2011 & 103 \\
Total & 483 & Total & 512 \\
\hline
\end{tabular}

Table 4. Correlations between maximum SNs, SRFs, SIs, and SPEs with earthquake numbers (exact and nearest values).

\begin{tabular}{lc}
\hline Earthquake maximum solar activity & $(\mathbf{M} \geq 4)$ \\
\hline Sunspots numbers (SNs) & 0.52 \\
Solar 10.7 cm Flux (SRFs) & 0.27 \\
Solar irradiance (SIs) & 0.53 \\
Solar proton events (SPEs) & -0.98 \\
\hline
\end{tabular}

number of local earthquakes are correlated with maximum annual means of $\mathrm{SN}$ and $\mathrm{SI}$, with positive correlation coefficients of $(0.52)$ and $(0.53)$ respectively but for SPE it is a negative and strong value of $(-0.98)$ (Table 4).

3. In the minimum years of solar activities, the total number of local earthquakes also are correlated with minimum annual means of SN and SRF with very good and negative correlation coefficients of $(-0.98)$ and $(-0.96)$
Table 5. Correlations between minimum solar activities (SNs, SRFs, Sis, SPEs) with ENs.

\begin{tabular}{lc}
\hline Earthquake minimum solar activity & $(\mathbf{M} \geq \mathbf{4})$ \\
\hline Sunspots Numbers (SNs) & -0.98 \\
Solar 10.7 cm Flux (SRFs) & -0.96 \\
Solar Irradiance (Sls) & 0.86 \\
Solar proton events (SPEs) & -0.50 \\
\hline
\end{tabular}

respectively. But for $\mathrm{SI}$, it is a positive value of $(0.86)$ (Table 5).

The positive and negative correlation coefficient shows direct and inverse physical relationship respectively. The correlation coefficient of SPE-EF is always negative. In the years of maximum solar activity, very high energy charge particles (protons) leave from sun and move to Earth's atmosphere and consequently to its surface. All 
discussion in this research work is considered only for Iran as local earthquakes.

\section{CONCLUSION}

It is expecting that different regions show different results because the Earth is not a homogeneous and isotropic object and therefore different regions have different tectonic properties. Finally we find out that solar activities may play an external effect on earthquakes occurrence.

\section{ACKNOWLEDGEMENTS}

The authors would like to thank the authority of Incorporated Research Institutions for Seismology (IRIS) and National Oceanic Atmospheric Administration (NOAA) for their useful data. We also thank Mrs Misha Nikouravan for her assist.

\section{REFERENCES}

Courtillot V, Gallet Y, Le Mouël JL, Fluteau F, Genevey A (2007). Are there connections between the Earth's magnetic field and climate? Earth Planet. Sci. Lett., 253(3): 328-339.

Georgieva KY, Kirov BB, Antanasov D. (2003). On the relation between solar activity and seismicity. pp. 236-240.

Ip WH (1976). Chinese records on the correlation of heliocentric planetary alignments and earthquake activities. Icarus, 29(3): 435436.
Khain V, Khalilov E (2007). About Possible influence of solar activity upon seismic and volcanic activities: Long-term forecast. Trans. Int. Acad. Sci., pp. 217-240.

Khain V, Khalilov E (2009). About possible influence of solar activity on seismic and volcanic activities: long-term forecast. Science without borders, p. 316.

Lursmanashvili O (1972). On the Possible Influence of Solar Activity on the Distribution of Earthquakes in the Caucasus. Reports (Soobshcheniya) of the Acad. Sci. Georgian SSR, Q(2).

Manuel OK, Ninham BW, Friberg SE (2002). Superfluidity in the solar interior: Implications for solar eruptions and climate. J. Fusion Energy, 21(3): 193-198.

Odintsov S, Boyarchuk K, Georgieva K, Kirov B, Atanasov D (2006). Long-period trends in global seismic and geomagnetic activity and their relation to solar activity. Phys. Chem. Earth, Parts A/B/C, 31(13): 88-93.

Simpson JF (1968). Solar activity as a triggering mechanism for earthquakes. Earth Planet. Sci. Lett., 3: 417-425.

Sitinskiy A $(1973,1998)$. About influence of solar activity upon Earth seismicity. USSR Academy of Science reports. 208(5).

Zhang GQ (1998). Relationship between global seismicity and solar activities. Acta Seismologica Sinica, 11(4): 495-500. 